\title{
Endogenous Economic Growth: The Arrow-Romer Theory and a Test on Vietnamese Economy
}

\author{
NGUYEN NGOC THACH \\ Institute for Research Science and Banking Technology, Banking University HCMC, \\ Ho Chi Minh City 70000 \\ VIETNAM
}

\begin{abstract}
The Arrow-Romer growth model helped to overcome the main drawback of the Solow-Swan model, where technical change is created exogenously, not by the firms making decisions, and formulated the conditions for endogenous growth in an economy. Nonetheless, the presentation of the Arrow-Romer model and corresponding empirical studies by the Cobb-Douglas functions hides the role of the capital-labor relationship for economic growth. A constant elasticity of substitution (CES) function, constructed by Arrow et al. (1961), allows solving this problem. So, the purpose of the current research is to test the endogenous growth of the Vietnamese economy, which has experienced a more than 30-year market-oriented reform through specifying an aggregate CES function. By applying Bayesian nonlinear regression, the research results revealed the elasticity of factor substitution (ES) lower than one. This work theoretically and empirically contributes to the endogenous growth theory in problems concerned with emerging economies. Investments in physical and human capital and technological progress are the determinants of endogenous growth. From the findings obtained, the author concludes that even though having achieved a rather impressive growth rate over more than three decades, the Vietnamese economy has not yet generated the possibility of endogenous growth, and suggests that endogenous growth can be hardly generated in emerging economies like Vietnam if important growth policies related to accumulation of physical and human capital as well as enhancement of R\&D activities are not simultaneously implemented. It is indispensable to focus on substantially improving institutional quality.
\end{abstract}

Key-Words: - Arrow-Romer model, endogenous growth, Vietnamese economy, Bayesian nonlinear regression.

Received: November 17, 2019. Revised: May 4, 2020. Accepted: May 6, 2020. Published: May 10, 2020.

\section{Introduction}

Economic growth is one of the most important themes in economics. Indeed, the welfare of future generations significantly depends on how fast an economy grows at present. A small difference in growth rate across countries can lead to an enormous gap in per capita income between them in the future. Most of modern growth theories, from the Solow-Swan to the Arrow-Romer model, have used the Cobb-Douglas production to analyze this most influential phenomenon. The remarkable achievement of the modern growth models, to say rightly, is to prove technical change, exogenous or endogenous, to be the source of economic growth, and more specifically, find an indispensable condition for sustainable endogenous growth. Although these theories are consistent with observed data, the popular use of the Cobb-Douglas does not allow for exploring the extremely crucial role of the ES for economic growth. In the meantime a great amount of theoretical and empirical studies claim that there is a positive relationship between the ES and economic growth. So, the CES function, which appeared in 1961, c ould help solve the mentioned problem.

Vietnam, considered a new growth phenomenon of the global economy at the beginning of the $21^{\text {th }}$ century and entering the NEST then EAGLEs group, has performed high economic growth since 1986, when this country began extensive marketoriented reforms. In fact, Vietnam has achieved an average growth rate of $6.5 \%$ over the period from 2000 to 2016 (Federal Reserve Bank of St. Louis, 2019). However, investigating the determinants contributing to the economic growth of Vietnam, the large majority of studies employed the CobbDouglas functions, so could not explore the impact of the ES on the growth process. Moreover, the author of this paper found no research attempting to analyze the possibility of the endogenous growth of the Vietnamese economy. Also note that most of these studies used the outdated frequentist methods, 
which have been sharply criticized for several shortcomings.

For above analyzed reasons, the author will conduct a research work to test the possibility of endogenous growth for the Vietnamese economy based on a CES framework via the Bayesian nonlinear regression.

The remainder of the paper is structured as follows. Section $2 \mathrm{i}$ ntroduces the theoretical framework and related empirical studies on the association of the ES with economic growth. Section 3 de scribes research methods, model specification and data. Bayesian simulation results are presented in Section 4. Section 5 includes the conclusion.

\section{Theoretical Framework and Related Studies}

\subsection{Solow-Swan Model versus Arrow-Romer Model}

The modern theory of economic growth experienced two periods of rapid development. The first occurred in the 1950s and 1960s, when the theory of exogenous growth was created, represented by the Solow-Swan model, the Ramsey model and the model of overlapping generations. Because, as growth models, the Ramsey model and the model of overlapping generations did not advance us far, in other words, their logic in the end still comes down to the paradigm of the Solow model, i.e., the law of positive and diminishing marginal productivities. After two decades of lull in this field, the second period came in the 1980s, when the theory of endogenous growth appeared, which in the coming decades expanded into several subsections.

Explaining the growth phenomenon, modern theories of the first generation are presented in the well-known exogenous models. In the Solow-Swan model (Solow, 1956; Swan, 1956) that made up the foundation of the modern growth theory, per capita income grows through investment in physical capital and ac orresponding increase in capital capacities on one employee until reaching a stationary state, in which GDP per capita is constant, and GDP can rise only due to population expansion. The essence of the Solow-Swan model is simple. It describes the accumulation of physical capital in the economy producing an aggregate product $\mathrm{Y}$, from which the share $\mathrm{S}$ is saved and converted into investments, and the share 1-s goes to consumption. The final product is produced exploiting two factors of production - capital and labor. If we consider the labor force to be constant, then economic growth can go only owing to the accumulation of physical capital that takes place as a result of investments. However, the Solow-Swan model showed that such a source of growth is limited. To do this, one very logical and important assumption must be made - the ever-diminishing marginal product of capital capacities. With a constant labor force, each additional machine gives less and less marginal product, because there is no one to work on. I $\mathrm{n}$ other words, while capital accumulates, the economy grows, but at a declining rate. However, even worse is the fact that machines and equipment are all the time eliminated as a consequence of depreciation and they must be replaced, spending a share of the investment on this. As capacities accumulate, this proportion increases all the time, until it becomes one. Then all investments will be spent on replenishing a h uge reserve of constantly depreciating capacities, and their growth is being installed. The economy loses the only source of growth and goes into a stationary state. The modification of the Solow-Swan theory allows one to take into account "exogenous technical progress". With such technical progress we can get away from the problem of diminishing marginal productivities and to continue investing in new production capacities. In this case, per capita GDP in the steady state will grow at the rate of technical progress. Everything in this model, however, is exogenous: people save the exogenous share of income s, technical progress is going on at an exogenously given rate, and if the population is growing, it is also at some given rate.

The Solow-Swan model provides a simple prediction about that the convergence of per capita GDP will take place, i.e. countries with lower level of labor productivity should grow faster and eventually catch up with leading ones in terms of income per capita. And this prediction seemed rather exact in 1960s. However, in the 1980s it began to raise doubts: developed countries grew more quickly than developing ones. In the former, income growth rates and technological progress have accelerated together. Besides, exogenous models could not explain observed facts corresponding to the assumption of diminishing returns to the main production factors - capital and labor. In real life, there are some industries that experienced no de crease in returns to inputs upon reaching a certain level of capital. So, in the exogenous growth theory, long-run economic growth is acquired not due to the decisions made by economic agents, but exogenous technological progress. 
The main idea of the growth theories of the second generation is that new knowledge created in investment by a firm instantaneously and costlessly spills over others, and, in turn, this firm benefits from all the remaining firms' investments. As a result, returns to investment cease to be diminishing for the whole economy. That is the essence of Paul Romer (1986, 1987)'s endogenous growth theory, interest in which has already manifested itself again in the 1980s. This author decided to formulate a growth model, in which there would be sustainable long-run economic growth without assuming exogenously given technical progress. Romer wondered how to make endogenous the main source of growth, technical progress. 'Cause it doesn't just fall from heaven, it, like everything else in the economy, is the result of decisions and actions of optimizing players. His ideas originated from Arrow's "learning-by-doing" hypothesis (Arrow, 1962), according to which the accumulation of knowledge (new methods to produce more effectively, skills to apply them in production) is a by-product of mechanization (expressed by capitallabor ratio). Firms decide on physical investment, seeking to maximize long-term profit. Investments in physical capital simply bring firms great production opportunities in the future, as in the models of the 1960s, but they are also limited by diminishing marginal productivities. Production environment changes when a new machine is equipped. The firm's workers learn the latest techniques by operating it and more specifically, while learning to operate the new equipment, they discover new forms of production organization and look for new ideas to improve upon it. In other words, when a firm's level of mechanization increases, its stock of knowledge also grows through the "learning-by-doing" process. Hence, $A_{i t}$ increases at $\gamma$ percent each 1 percent increase in $K_{i t} / L_{i t}$ :

$$
A_{i t}=\varphi\left(\frac{K_{i t}}{L_{i t}}\right)^{\gamma}
$$

where $A_{i t}$ is a firm's stock of knowledge, $\frac{K_{i t}}{L_{i t}}$ is its capital-labor ratio (level of mechanization), $\gamma$ is the learning-by-doing elasticity of $A_{i t}$ with respect to $\frac{K_{i t}}{L_{i t}}$ and positive, $\varphi$ is a parameter, $i=1,2, \ldots, N$.

Combining Arrow's "learning-by-doing" hypothesis with the "knowledge spillover" hypothesis, Romer constructed an insightful growth theory, which is largely famous later as the ArrowRomer model. The "knowledge spillover" hypothesis shows that knowledge leaks out instantaneously and all firms can access it costlessly. As already mentioned, the knowledge obtained by each firm through its own "learning-bydoing" will disseminate to all other firms, but at the same time this firm also benefits from the knowledge the latter firms create in their learningby-doing" process. So, at any time $t$ all firms possess the same level of knowledge, which equals the economy-wide knowledge, $A_{t}$ :

$$
A_{i t}=\varphi\left(\frac{K_{i t}}{L_{i t}}\right)^{\gamma}=A_{t}
$$

From this expression it follows that $A_{t}=$ $\varphi\left(\frac{K_{t}}{L_{t}}\right)^{\gamma}$, i.e. all firms have the same capital-labor ratio, which is equivalent to the aggregate capitallabor ratio. Specifically, Equation (2) indicates that the level of knowledge is no 1 onger exogenously determined. It is dependent on the capital-labor ratio decided by the firms and hence, is endogenous.

Arrow and Romer's endogenous growth theory can be described by an individual Cobb-Douglas production function as follows:

$$
Q_{i t}=K_{i t}^{\alpha}\left(A_{t} L_{i t}\right)^{1-\alpha}, \quad 0<\alpha<1 .
$$

Note that Equation (3) is a strictly neoclassical function with constant returns to scale (CRTS) and positive and diminishing $M P K$ and $M P L$. By simple summation of all the individual production functions, we obtain an aggregate production function:

$$
Q_{t}=K_{t}^{\alpha}\left(A_{t} L_{t}\right)^{1-\alpha} .
$$

As we know, $k_{t}=\frac{K_{t}}{L_{t}}$, so:

$$
\begin{gathered}
\Delta k_{t}=\frac{d k_{t}}{d t}=\frac{\left(d K_{t} / d t\right) L_{t}-\left(d L_{t} / d t\right) K_{t}}{L_{t}^{2}}= \\
s q_{t}-(\delta+n) k_{t},
\end{gathered}
$$

where $\delta$ is the depreciation rate, $n$ is the growth rate of population, and

$$
q_{t}=A_{t} \frac{Q_{t}}{L_{t}}=\left(\frac{K_{t}}{L_{t}}\right)^{\alpha} L_{t}^{1-\alpha}=a k_{t}^{\alpha+\gamma(1-\alpha)}
$$

$$
\text { where } \varphi^{1-\alpha}=a \text {. Hence, from (5), we have: }
$$

$$
\begin{aligned}
& \Delta k_{t}=\operatorname{sak}_{t}^{\alpha+\gamma(1-\alpha)}-(\delta+n) k_{t} . \\
& \text { So we obtain: } \\
& \dot{k}_{t}=\frac{\Delta k_{t}}{k_{t}}=s a k_{t}^{[\alpha+\gamma(1-\alpha)]-1}-(\delta+n) .
\end{aligned}
$$

Note that $\dot{k_{t}}$ is the growth rate of the capitallabor ratio, which will be constant only if $\alpha+$ $\gamma(1-\alpha)=1$, i.e. only if $\gamma=1$ or in other words, the elasticity of learning-by-doing" equals one. Then, the aggregate production function becomes the following:

$$
Q_{t}=a K_{t}
$$

Equation (9) is a type of "AK model", where output is proportional to the capital stock as $a$ is a constant of proportionality.

From Equations (6) and (8), with $\gamma=1$, we have: $\dot{k_{t}}=\dot{q}_{t}=s a-(\delta+n)>0 . \gamma=1$ is not yet a necessary and sufficient condition for endogenous growth. With $\gamma=1$ the economy grows 
endogenously as long as $s a-(\delta+n)>0$. Our model has a balanced growth steady state. We easily prove that:

$$
\dot{k_{t}}=\dot{q_{t}}=\dot{c}=i=s a-(\delta+n) .
$$

In the steady state, per capita variables grow at the same rate and so will level variables:

$$
\dot{K}=\dot{Q}=\dot{C}=\dot{I}=s a-\delta \text {. }
$$

Let us make an important remark. An AK-type economy always is in steady state, thus it does not have any dynamics towards the long-run equilibrium, i.e. the long-run equilibrium and the short-run equilibrium are the same in this economic system. From Equation (9), $Q_{t} / K_{t}=a=$ constant. Since $\dot{K}=\dot{Q}$ and $\frac{Q_{t}}{K_{t}}=$ constant at all $t$, an AK-type economy is permanently in steady state. Note that the steady state must not be the same. A higher savings rate or stronger international integration causes the steady state path of the economy shift to a new steady state and this effect is permanent compared with the Solow-Swan model. The effects of changes in the growth rate of population and capital depreciation on e conomic growth is opposite.

The Arrow-Romer model confronts the problem of so-called observational equivalence, i.e. the same data are consistent with some theories. As stated rightly by Solow (1997, p.16), "all but impossible to make a co nvincing empirical case. Observations consistent with constant returns to capital would inevitably also be consistent with a fair range of increasing and decreasing returns to capital". Besides, the use of the Arrow-Romer model leads to a too rigid endogenous growth condition, that is exactly $\gamma=1$.

\subsection{Endogenous Growth Conditions in the CES}

Before considering the CES specifications, let us briefly analyze the Cobb-Douglas. The work of Cobb and Douglas (1928) is viewed as a turning point in the theory of production functions. Though some studies on production functions appeared before (see the reviews by Stigler (1952), Schumpeter (1954), Barkai (1959), Lloyd (1969), Velupillai (1973), Samuelson (1979), Humphrey (1997), for the first time the connection between capital and labor and output is formulated in a mathematical form and empirically verified. After Paul Douglas requested math professor Charles Cobb to form an equation depicting the relationship between the mentioned factors utilizing time series data on the U.S. manufacturing industries, a joint article came into sight, where the production function fits the observed data. The initial CobbDouglas function is the following:

$$
y=A x_{1}^{\alpha} x_{2}^{1-\alpha} .
$$

Solow $(1956,1957)$ was a pioneer of the modern growth theory, and his followers such as Arrow (1962) and Romer $(1986,1987)$ made use of the Cobb-Douglas specifications with the ES permanently equal to one, and thus the role of the ES was ignored. Nonetheless, changes in the ES were revealed by lots of empirical studies in the past and the present. For instance, on a su rvey carried out by Nerlove (1967), it was found that the ES may get different values if estimation samples or methodologies vary. Using five different measures of the rental price of capital, two estimation methods, and six alternative production functions to estimate the ES, Berndt (1976) provided a similar conclusion. Testing the constancy of the ES for the steam-electric generating industry, McFadden (1978) found that its estimate equals a value of approximately 0.75 . Hamermesh (1993) revealed that the ES changes in a range from 0.49 to 6.86 for the UK and from 0.32 to 1.16 for the US. Among others, Pitchford (1960), Azariadis (1993), and Galor (1995) found an ES smaller than one in the CES. Yuhn (1991) and Cronin et al. (1997) aimed at testing the connection between the ES and economic growth. Yuhn (1991) revealed that a higher ES helps explain the higher growth rates achieved by South Korea after the 1960s, whereas using data set covering the period of 1961-1991, Cronin et al. (1997) estimated an ES of 13.01 b etween capital and telecommunication.

Accounting for the shortcomings of the CobbDouglas, growth economists sought to construct a new type of production function with a flexible ES. In 1961, Arrow et al. (1961) proposed the first CES function:

$$
F(K, L)=\gamma\left(\alpha K^{-\rho}+(1-\alpha) L^{-\rho}\right)^{\frac{-1}{\rho}}
$$

where $\rho=\frac{1-b}{b}$ is substitution parameter, $\alpha=a_{1} \times$ $\gamma^{\rho}$ is distribution parameter; $\gamma$ is efficiency parameter, the ES, $\sigma=\frac{1}{1+\rho}$.

Equation (13) must satisfy the following conditions: $0<\alpha<1 ; \gamma>0 ; \rho>-1$ to be a neoclassical function. The proposition of Hicksneutral technical progress means that the output produced by capital and labor is supposed to grow exponentially in a way that does not change the marginal rate of technical substitution between these inputs. Hence, the parameters of the CES are stable over time. In addition, one more advantage of the CES is its adaptability to various sample periods in empirical investigations. 
If $\sigma>1(-1<\rho<0)$, then capital and labor are substitutable, and thus growing $K / L$ will raise capital share. In case $\sigma<1(0<\rho<\infty)$, capital and labor are complementary, and hence, labor share rises along with increases in $K / L$. If $\sigma=1$ $(\rho=0)$, then the Cobb-Douglas is obtained.

Regarding the role of the ES for the process of economic growth, many theoretical and empirical studies were implemented. According to Thach (2020), as to demonstrate the positive effect of the ES on economic growth, we can use a 2-factor linear homogenous production function with Hicksneutral technical change $(A)$ :

$$
y=A(t) F(K, L)
$$

Differentiating (14), we obtain:

$\frac{d y}{d t}=\frac{\partial A}{\partial t} F(K, L)+A \frac{\partial F}{\partial K} \times \frac{\partial K}{\partial t}+A \frac{\partial F}{\partial L} \times \frac{\partial L}{\partial t}$

Since $1-\alpha=\frac{\partial y}{\partial K} \frac{K}{y}, \alpha=\frac{\partial y}{\partial L} \frac{L}{y}$, the rate of economic growth is written as follows:

$$
\frac{\Delta y}{y}=\frac{\Delta A}{A}+(1-\alpha) \frac{\Delta K}{K}+\alpha \frac{\Delta L}{L}
$$

Hence, we have:

$$
g_{y}=g_{A}+g_{k}+\alpha\left(g_{l}-g_{k}\right)
$$

The elasticity of production with respect to labor is expressed as a function of the ES:

$$
\alpha=(1-\alpha) \frac{w / r}{K / L}, w=\frac{\partial y}{\partial L}, r=\frac{\partial y}{\partial K},
$$

or in logs and differentiating with respect to time:

$\frac{d \ln \alpha}{d t}=\frac{d \ln (1-\alpha)}{d t}+\frac{d \ln (w / r)}{d \ln (K / L)} \times \frac{d \ln (K / L)}{d t}-\frac{d \ln (K / L)}{d t}(19)$

We know:

$$
\frac{d \ln (w / r)}{d \ln (K / L)}=\frac{1}{\sigma}
$$

Hence

$$
\frac{d \ln \alpha}{d t}=\frac{d \ln (1-\alpha)}{d t}+\frac{d \ln (K / L)}{d t}\left(\frac{1-\sigma}{\sigma}\right)
$$

and

$$
\frac{\Delta \alpha}{\alpha}=-\frac{1}{1-\alpha} \Delta \alpha+\frac{1-\sigma}{\sigma}\left(\frac{\Delta K}{K}-\frac{\Delta L}{L}\right)
$$

Thus, we have:

$$
\Delta \alpha=\alpha(1-\alpha) \frac{\sigma-1}{\sigma}\left(g_{l}-g_{k}\right)
$$

Let us assume the constant rates of technical progress and the inputs, the rate of economic growth $\left(g_{y}\right)$ may change only due to variations in $\alpha$. From Equations (17) and (21), we obtain:

$$
\frac{d g_{y}}{d t}=\alpha(1-\alpha) \frac{\sigma-1}{\sigma}\left(g_{l}-g_{k}\right)^{2}
$$

In case $g_{l} \neq g_{k}$, then the sign of Equation (24) will be positive if $\sigma>1$ and negative if $\sigma<1$. Therefore, the magnitude of the ES effects depends on the difference between the growth rates of capital and labor. In case $g_{l} \approx g_{k}$, the variation of $g_{y}$ over time is not considerable or the effect of the ES on economic growth rate is weak.

Moreover, Heubes (1972) claimed that not only the time path but also economic growth rate are functions of the ES. Differentiating (17) with respect to time and $\sigma$ to get for small $d t$ and $d \sigma$, we have:

$$
\begin{aligned}
& d g_{y}=\left(\frac{\partial \alpha}{\partial t} d t+\frac{\partial \alpha}{\partial \sigma} d \sigma\right)\left(g_{l}-g_{k}\right) \\
& =\left\{\alpha(1-\alpha)\left(g_{l}-g_{\text {睮 }}\right) d t-\frac{c \alpha}{\sigma^{2}} \frac{\ln (K / L)}{c+(K / L)^{\frac{1-\sigma}{\sigma}}} d \sigma\right\} \times \\
& \left(g_{l}-g_{k}\right)
\end{aligned}
$$

If $g_{l}>g_{k}\left(g_{l}<g_{k}\right)$ and $K / L<1(K / L>1)$, then a higher rate of economic growth corresponds to a greater ES. Thus, $\frac{\delta g_{y}}{\delta \sigma}>0$. In case the ES is small, a strong impact of the relatively scarce input on output arises for its elasticity of production is large. With the growth of $\sigma$, the elasticity of production decreases for the scarce input, but it rises for the relatively abundant factor. The effect of the ES variation on the rate of economic growth becomes weak for high levels of the ES. The growth rate is independent of the ES when $K / L=1$.

In order to verify whether economic growth is endogenous, it is important to formulate theoretically the conditions for this. Recall that in the Arrow-Romer model, the elasticity of "learningby-doing" equal to one is proven as the prerequisite for an economy to grow endogenously (together with the additional condition: $s a-(\delta+n)>0)$. Once we acquire the ES estimate, we can test the endogenous growth condition in the framework of the CES. By dividing both sides of Equation (13) by $L$, we get an expression for output per capita:

$$
\frac{F(K, L)}{L}=f(k)=\gamma\left[\alpha k^{-\rho}+(1-\alpha)\right]^{\frac{-1}{\rho}} .
$$

From Equation (26), we obtain the marginal and average products as follows:

$$
f^{\prime}(k)=\gamma \alpha\left[\alpha+(1-\alpha) k^{-\rho}\right]^{\frac{(1-\rho)}{\rho}} .
$$

and

$$
\begin{aligned}
& \frac{f(k)}{k}=\gamma \alpha\left[\alpha+(1-\alpha) k^{-\rho}\right]^{\frac{1}{\rho}} . \\
& \text { As we know: } \\
& \Delta K=I-\delta K=s F(K, L, t)-\delta K .
\end{aligned}
$$$$
\text { or }
$$$$
\frac{\Delta K}{L}=s f(k)-\delta k \text {. }
$$

Using the condition:

$$
\Delta k=\frac{d(\mathrm{~K} / \mathrm{L})}{d t}=\frac{\Delta K}{L}-n k, \quad n=\frac{\Delta L}{L} .
$$

Substituting (31) into (30) and dividing by $k$, we obtain the growth rate of $k$ :

$$
\frac{\Delta k}{k}=\frac{s f(k)}{k}-(n+\delta) \text {. }
$$

In the CES, the growth rate of an economy will depend on the substitution parameter $(\rho)$ as the marginal and average products are dependent on this parameter. It is easy to prove that if a d egree of substitution is high $(\sigma>1)$, the limits of the marginal and average products are: 
$\lim _{k \rightarrow \infty}\left[f^{\prime}(k)\right]=\lim _{k \rightarrow \infty}[f(k) / k]=\gamma \alpha^{\frac{-1}{\rho}}>$ $0,(33)$

$\lim _{k \rightarrow 0}\left[f^{\prime}(k)\right]=\lim _{k \rightarrow 0}[f(k) / k]=\infty$.

Hence, the marginal and average products do not go to zero as $k$ increases over time. As stated by Pereira (2003), the ES can be interpreted as an index of the rate at which diminishing marginal returns set in as one factor is raises relative to the other. If the ES is great, then substituting one factor for the other or increasing output by increasing one factor is easy. Therefore, diminishing marginal returns will set in slowly or not set at all, or in other words, the larger the ES the smaller the drag due to diminishing returns. In this case, from Equation (32), we can achieve endogenous growth as long $\frac{s f(k)}{k}>$ $(n+\delta)$ or $s \gamma \alpha^{\frac{-1}{\rho}}>(n+\delta)$. We easily see that if the ES is less than one, the marginal and average products approach zero as the capital-labor ratio approaches infinity and thus, the model does not generate the possibility of endogenous growth.

\subsection{Empirics on Impact of Substitution Elasticity on Economic Growth}

The role of the ES has long been recognized in many branches of economics, specifically in growth literature. In early growth theory, several researchers tried to prove the importance of the ES. La Grandville (1989) was the first to systematically analyze the relationship between the ES and economic growth. He theoretically proved that at any stage of economic development, the growth rate of per capita income is an increasing function of the ES. Ferguson (1965) documented that in the case of an ES different from one, the economic growth rate depends on the ES and the rate of savings ratio growth. The use of the Slutsky equation by $\mathrm{La}$ Grandville (1989) produced the similar evidence on the positive relationship between the ES and economic growth: a greater ES allows for achieving a higher production level. Two investigations resting on La Grandville carried out by Yuhn (1991) and Cronin et al. (1997) were aimed at verifying the link between the ES and economic growth. Performing comparative analysis of the US and South Korea economies, Yuhn (1991) revealed that the ES was greater for South Korea, which supports the fact that this economy acquired the higher growth rate since the 1960s. Based on data set for the period of 1961-1991, Cronin et al. (1997) found the elasticity estimate of 13.01 between capital and telecommunication. Changes in the ES affect growth rate since production is an increasing function of the ES.

According to Solow (1957), Pitchford (1960), and Sato (1963), letting the ES receive any value will lead to multiple growth paths, some of which will be unbalanced, i.e. level or rate variables are not the same. Azariadis (1993), applying the Diamond overlapping generations model of growth, pointed at the possibilities of poverty traps dependent on the elasticity values. Barro and Sala-iMartin (1995) argued that under certain conditions, a high ES can create endogenous, steady-state growth in an economy. In case of the ES more than one, a unique steady-state and possibility of endogenous growth can be achieved (Barro and Sala-i-Martin 1995). While, according to Pitchford (1960), Azariadis (1993), and Galor (1995), an ES lower than one in a CES specification can cause multiple steady-states and poverty traps for per capita output. Later, Klump and La Grandville (2000) ensured that a greater ES generates more probable endogenous growth and higher long-term growth rates. Also, the higher the ES, the greater steady-state income per capita. Using a simple CES model, Klump and Preissler (2000) also found that a higher ES leads to a higher steady state and makes permanent growth more probable. For the CES specifications, the ES affects economic growth in almost every case, except when capital and labor are increasing at the same pace (Kamien and Schwartz 1968). Generally, we can see the similarity of the results in the above empirical investigations.

The majority of studies on economic growth in Vietnam access $f$ requentist statistics or the accounting method to specify Cobb-Douglas functional forms. As well known, this type of production function has an ES exactly equaling one. Applying the standard Cobb-Douglas function, Tu and Nguyen (2012) analyzed the influence of factor inputs on coffee productivity in DakLak province. By applying the accounting method, Nguyen (2013) specified a Cobb-Douglas function to examine the resources of economic growth of Hung Yen province. The research goal of Khuc and Tran (2016) is to identify the determinants of Vietnam's industry growth through an extended Cobb-Douglas function. Le applying the accounting method specified a Cobb-Douglas function for Vietnam on micro data of three industries: mining; processing industry; electricity and water production and distribution. The estimation results demonstrated that the proportion of labor and fixed assets in the 
output of the researched sectors varies from 0.11 to 0.39 and 0.89 to 0.61 , respectively.

Some researchers specified other types of the Cobb-Douglas. For example, among others, Pham and Ly (2016) built a translog Cobb-Douglas function for the manufacturing sector of Vietnam on a data set taken from the 2010 Vietnam Enterprise Survey by the General Statistics Office. Huynh (2019) utilized the MLE method on a data set also extracted from the Enterprise Survey of the General Statistics Office over a span of 2013-2016 to specify a Battese-Coelli production function and elaborate upon the factors impacting on technical efficiency of Vietnamese small and medium enterprises.

\section{Methodology and Data}

\subsection{Methods and Model Specification}

In order to test the endogenous growth condition, we need to estimate the ES via specifying an aggregate CES production function. There are direct and indirect methods, which can be applied to estimate the ES. By a d irect method the ES is estimated via the specification of a production function. The indirect method explores the relationship between the ES and factor shares to obtain the estimates. Following Mizon (1977), we choose the direct method for this technique gives estimates for a great amount of functional forms utilizing a common method and data set.

It is noteworthy that most of the above mentioned previous studies evaluated the ES based on the frequentist approach accessing the CES or the VES, which might give unreliable results and more importantly, could not provide straightforward probability explanations for estimations. In the recent decades, Bayesian statistics has been more and more widely used in humanity and social sciences due to some its important strengths (Anh et al., 2018; Kreinovich et al., 2019; Hung et al., 2019; Briggs and Hung, 2019; Thach, 2000c; Thach, 2000b; Thach, 2000c). Among the advantages of the Bayesian perspective over the traditional frequentist approach, we can say, first of all, the great strength of the Bayesian approach is its universality as the Bayesian rule allows for using all types of statistic models, while within the frequentist framework a method designed for a model class is often irrelevant to other classes. Second, the results of Bayesian inference give straightforward probability interpretations as compared to classical econometrics. When applying noninformative prior, we strive to include vague prior information in the model of interest. With informative priors, much of information is incorporated in the model. Though with the use of noninformative or weakly informative priors the results will be similar, their interpretations differ. Confidence intervals imply that, if the experiment is repeated billions of times, then $95 \%$ of the experiments will capture the population parameter in their confidence intervals. But we cannot report we have a $95 \%$ probability of capturing it. Bayesian credible intervals, on the other hand, enable us to claim that there is a $95 \%$ probability that the true value belongs to the interval. Third, besides, let us believe one reason to perform a B ayesian analysis is that Bayesian inference provides us with af ull posterior distribution, which can result in more detailed intervals than the typical frequentist $\pm 2 \sigma$. Producing an entire posterior distribution of model parameters is one more strength of the Bayesian framework over frequentist methods, which yield only a point estimate of the parameters derived from a likelihood function, and access a quadratic approximation of the log-likelihood function and asymptotic normality assumptions to depict uncertainties. With the Bayesian approach, we do not need to make use of any approximation to evaluate the uncertainties because the entire posterior distribution of the parameters is available. For these reasons, in this work, we apply the Metropolis-Hasting algorithm and Gibbs sampling as simulation-based methods for parameter estimation within the Bayesian paradigm.

In the present study, employing the direct method, we estimate the ES through the specification of an aggregate CES function. For this, the Bayesian nonlinear regression relevant to accessing growth processes is performed. The Hicks-neutral technology terms, assumed to grow exponentially according to $\gamma=\gamma_{0} \exp \beta$ in the CES, denotes that the output produced by a combination of capital with labor is supposed to grow exponentially in a way that does not change the marginal rate of technical substitution between them. Hence, the parameters of the production function will be stable over time. Based on Equation (13), our nonlinear model is the following:

$$
\begin{aligned}
\ln Q=b_{0}+ & \delta \\
& -\frac{1}{\rho} \ln \left(\alpha K^{-\rho}\right. \\
& \left.+(1-\alpha) \mathrm{L}^{-\rho}\right)+\varepsilon .
\end{aligned}
$$

where $\ln Q$ is natural logarithm of output, $K$ and $L$ are capital and labor, respectively, $b_{0}=\ln \gamma_{0}, \rho$ is computed to calculate $\sigma=\frac{1}{1+\rho}, \varepsilon$ is a random error. Once $0<\alpha<1, \rho>-1$, Equation (35) is a neoclassical production function. 
Conditional probability is applied in Bayesian models:

$$
p(B)=\frac{p(A, B)}{p(B)} .
$$

to derive Bayes's theorem:

$$
p(A)=\frac{p(A \mid B) \times p(B)}{p(A)},
$$

where $A, B$ are random vectors.

Under the assumption that a data vector $X$ is a sample from a probability model with the unknown parameter vector $\theta$, the model is expressed using a likelihood function:

$$
\begin{gathered}
L L(\theta ; X)=f(X ; \theta)= \\
\prod_{i=1}^{n} f\left(X_{i} \mid \theta\right),
\end{gathered}
$$

where $f(\mathrm{X} \mid \theta)$ stands for a probability density function of $X$ given $\theta$. Given data $X$, we infer some properties of $\theta$. In Bayesian models, parameters $\theta$ is a random vector.

Bayesian analysis starts by specifying a posterior model. Since the posterior model combines given data and prior knowledge to show the probability distribution of all parameters, the posterior distribution consists of two components: A likelihood function incorporating information about the model parameters relying on observed data, and prior distribution, comprising knowledge about the parameters. Bayes' law allows combining the likelihood function with priors to compose the posterior model:

$$
\begin{gathered}
\text { Posterior } \propto \text { Likelihood } \\
\times \text { Prior }
\end{gathered}
$$

Both $X$ and $\theta$ are random variables, so Bayes's theorem is applied to derive the posterior distribution of $\theta$ given $X$ :

$$
\begin{gathered}
p(X)=\frac{p(X \mid \theta) p(\theta)}{p(X)}= \\
\frac{f(X ; \theta) \pi(\theta)}{m(X)},
\end{gathered}
$$

where $m(X) \equiv p(X)$ known as the marginal distribution of $X$ which is formulated as follows:

$$
\begin{aligned}
& m(X) \\
& =\int f(X ; \theta) \pi(\theta) d(\theta),
\end{aligned}
$$

where $f(X ; \theta)$ is a likelihood function of $X$ given $\theta$, $\pi(\theta)$ is a prior distribution for $\theta, m(X)$ is also known as the prior predictive distribution.

By experience, in fitting Bayesian models, priors can be selected resting on expert knowledge and previous studies. In the absence of prior information, vague or weakly prior distributions are often picked by researchers (Lambert et al., 2005). Weakly informative priors are used for reasonably regularizing parameter estimates and avoiding wrongly defined informative priors (Yang and Berger, 1998). In the current work, we consider earlier research results and the properties of a neoclassical function to derive weakly informative priors, which will make our Bayesian inference more robust. So, to specify the CES in the current research, examining Arrow et al. (1961), Lagomarsino (2017), and Thach (2020c), we set the normal $\mathrm{N}(0,100)$ prior on parameter $b_{0}$, the uniform $(0,1)$ prior on parameters $\delta$ and $\alpha$ (it is recommended for elasticity parameters), the gamma $(1,1)$ prior on parameter $\rho$, and the $\operatorname{Igamma}(0.001,0.001)$ prior on the variance parameter $\left(\sigma_{0}^{2}\right)$.

The Bayesian nonlinear regression model has the following form:

The likelihood function:

$$
\begin{aligned}
& \operatorname{lng} d p=b_{0}+\delta- \\
& \frac{1}{\rho} \ln \left(\alpha \mathrm{K}^{-\rho}+(1-\alpha) \mathrm{L}^{-\rho}\right)+ \\
& \varepsilon_{i j} .
\end{aligned}
$$

The prior distributions:

$$
\begin{gathered}
b_{0} \sim N(0,100) \\
\delta \sim \text { uniform }(0,1) \\
\alpha \sim \text { uniform }(0,1) \\
\rho \sim \operatorname{gamma}(1,1) \\
\sigma_{0}^{2} \sim \operatorname{Igamma}(0.001,0.001)
\end{gathered}
$$

\subsection{Data Description}

The author utilizes time series data covering the 17-year period from 2000 to 2016, c ollected from the Vietnamese General Statistics Office (2019)'s database and Penn World Tables introduced by the Federal Reserve Bank of St. Louis (2019). Time frequency indicates the year. Within Bayesian analysis, owing to combining prior information with observed data, inferential results are robust to sparse data, and hence a small sample does not influence MCMC simulation efficiency. Note that the 20002016 sample period includes years 2008-2009, when most of countries all over the world coped with a severe economic crisis, but the Vietnamese economy was much less hit by this global recession. According to statistical figures, the economic growth of Vietnam acquired good performance, $6.4 \%$, in 2009, and $6.2 \%$ in 2010 (Federal Reserve Bank of St. Louis, 2019). The figures of real GDP and stock of capital are calculated in constant 2011 prices. The units of GDP and stock of capital are a billion USD and of labor a million employees.

\section{Empirical Results 4.1 Descriptive Statistics}


Table 1 demonstrates that variables real GDP, $K$, and $L$ obtain maximum value of 608 (billion USD), 1,744 (billion USD) and 53 (million workers), minimum value of 223 (billion USD), 469 (billion USD), and 37 (million workers), mean of 391 (billion USD), 1035 (billion USD), and 46 (million workers), respectively. Standard deviation (Std. Dev) measures the variation or dispersion of a set of values. It equals 119,400 , and 37 for $G D P, K$, and $L$, respectively.

Table 1 Descriptive statistics

\begin{tabular}{|c|c|c|c|c|c|}
\hline Variable & Obs & Mean & Std.Dev & Min & Max \\
\hline GDP & 17 & 391.4 & 118.8 & 222.8 & 608.3 \\
K & 17 & 1034.7 & 399.6 & 469.3 & 1743.8 \\
L & 17 & 46.2 & 5.571 & 37.1 & 53.3 \\
\hline
\end{tabular}

\subsection{Bayesian Estimation Results}

In order to evaluate the efficiency of MCMC sampling in Bayesian modeling, we can use acceptance rate and efficiency as two main criteria. The acceptance rate is defined as the number of proposals accepted in the total number of proposals, whereas efficiency implies the mixing properties of MCMC sampling. Both these rates affect MCMC convergence. According to the results of Bayesian estimation in the current research, our specified model achieves a high acceptance rate of 0.6 , which is acceptable in view of Roberts and Rosenthal (2001). The model summary reports the smallest, average and largest efficiency of $0.03,0.13$ and 0.53 , respectively, which are more than the warning level of 0.01 (Table 2). Table 2 shows that the model parameters $b_{0}, \delta, \alpha, \rho$, and variance (ó $\left.o_{0}^{2}\right)$ obtain mean estimates of $-0.5,0.5,0.7,0.2$, a nd 0.0008 , respectively. Standard deviations for mean estimates are small and the posterior means have MC standard errors (MCSE) close to one decimal (the less these values, the more accurate the parameter estimates), which indicate the sufficiently high efficiency of our MCMC algorithm and the preciseness of the posterior estimates. Posterior confidence intervals in Bayesian analysis have a straightforward probability interpretation. For our model, for example, the probability of the posterior mean of parameter $b_{0}$ in the interval $(-0.12 ; 0.1)$ is $95 \%$. Parameters $\delta, \alpha, \rho$ have a strongly positive effect on the outcome since their credible intervals do not contain zero (Table 2).

Table 2 Estimation results of the model

\begin{tabular}{|c|c|c|c|c|c|c|}
\hline Parameters & Mean & Std. Dev. & MCSE & Median & \multicolumn{2}{c|}{$\begin{array}{c}\text { Equal-Tailed } \\
\text { [95\% Cred. Interval }\end{array}$} \\
\hline$b_{0}$ & -0.5451095 & 0.3339225 & 0.035071 & -0.5599943 & -1.16719 & 0.058721 \\
$\delta$ & 0.5250134 & 0.2851168 & 0.029361 & 0.5403358 & 0.0253621 & 0.9749141 \\
$\alpha$ & 0.7406754 & 0.0771262 & 0.007152 & 0.7254816 & 0.6312589 & 0.9372284 \\
$\rho$ & 0.1673064 & 0.1784752 & 0.019035 & 0.1152714 & 0.004851 & 0.6971241 \\
$\sigma_{0}^{2}$ & 0.0008585 & 0.000392 & $9.9 \mathrm{e}-06$ & 0.000773 & 0.0003975 & 0.0017726 \\
\hline
\end{tabular}

Our main results are in line with classical and recent empirical studies on the CES functions with Hicks-neutral technical change that revealed the elasticity of substitution between capital and labor is under unity in various samples for different intervals of time. Those are, typically, Arrow et al. (1961), Bodkin and Klein (1967), Berndt (1976) or Antràs (2004).

\subsection{Model Diagnosis}

In Bayesian analysis, MCMC convergence should be checked before we proceed to the inference stage, because the results of Bayesian inference will be valid once MCMC chains have converged to the stationary distribution. Then, our estimated parameters will converge to some reasonably fixed values. A good sequence mixing implies a real MCMC convergence. The results recorded in Figure 1 denote that with respect to our model, all necessary diagnostic graphs are acceptable. Cusum lines are jagged and not smooth, which certainly points to the sign of convergence (Fig.1a). ). Histogram plots reflect the shape of probability distributions (Fig.1b). Trace plots traverse rather quickly through the distribution towards the constant mean and variance, showing no trends (Fig. 1c), while autocorrelation plots die off after less than 40 lags (Fig. 1d). In sum, MCMC chains of our model mix well. Hence, we can conclude that no serious convergence problem exists.

Table 3 Effective sample size

\begin{tabular}{cccc}
\hline Parameters & ESS & Corr. Time & Efficiency \\
\hline$b_{0}$ & 90.66 & 33.09 & 0.0302 \\
$\delta$ & 94.30 & 31.82 & 0.0314 \\
$\alpha$ & 116.28 & 25.80 & 0.0388 \\
$\rho$ & 87.91 & 34.12 & 0.0293 \\
$\sigma_{0}^{2}$ & 1578.19 & 1.90 & 0.5261 \\
\hline
\end{tabular}


In addition to visual diagnostics, effective sample size is a formal test which can be commonly used for convergence inspection. Efficiency greater than one is referred to as satisfactory. Results

(a)

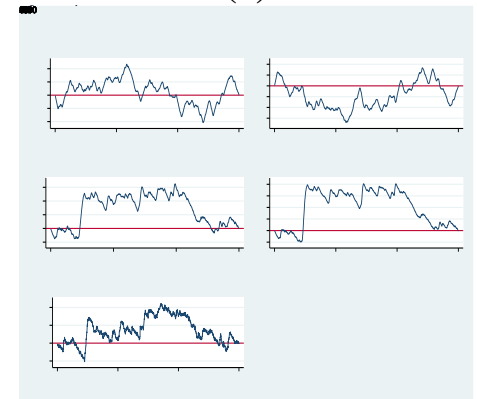

(c)

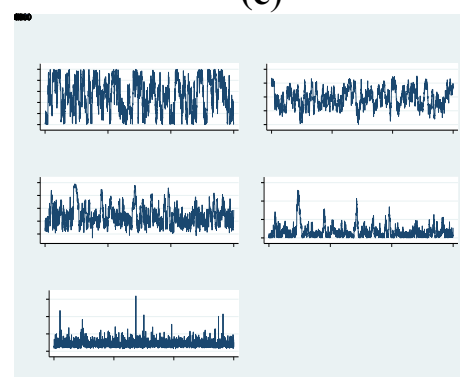

Fig. 1 Graphical diagnostics for MCMC convergence

\subsection{Estimate of Substitution Elasticity}

According to the results demonstrated in Table 2 , we obtain the estimates of the parameters $b_{0}=$ $0.5, \delta=0.5, \alpha=0.7$, and $\rho=0.2$. In Bayesian analysis, simulations do not produce point estimates in a frequentist sense. Checks for MCMC convergence ensure whether simulation results are robust. In the above, the convergence diagnostics provided acceptable results. Once Bayesian inference is robust, MCMC iterations will yield similar estimates for a particular parameter. The estimated coefficients satisfy the properties of a neoclassical function. Since $\rho>0$, the ES is less than unity $(0<\sigma<1)$. For case $\sigma<1$, we could provide some explanations for Vietnam's economic growth.

(i) Data set utilized in the present research indicates a marked difference between the growth rates of aggregate capital stock and labor input. The substitution elasticity smaller than unity yields the negative sign of (25). This empirical finding allows the author to conclude that the economic growth rate of Vietnam will exhibit a downward tendency in the long run if no break-through in growth policies is made. Note that compared to advanced and other emerging economies, Vietnam has a minor contribution of human capital and technical progress to production. According to the growth theories of Solow and Swan, Arrow and Romer, and several presented in Table 3 show no s ign of nonconvergence since the efficiency of all the parameters is more than 0.01 , while the highest correlation time is only 34 lags.

(b)

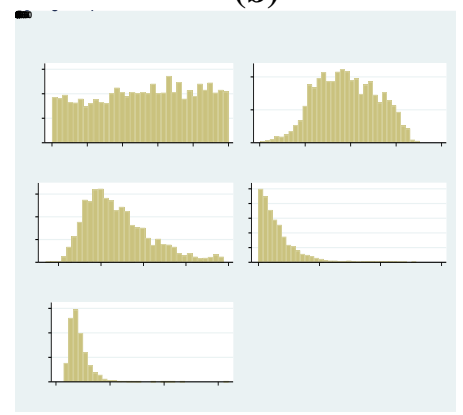

(d)

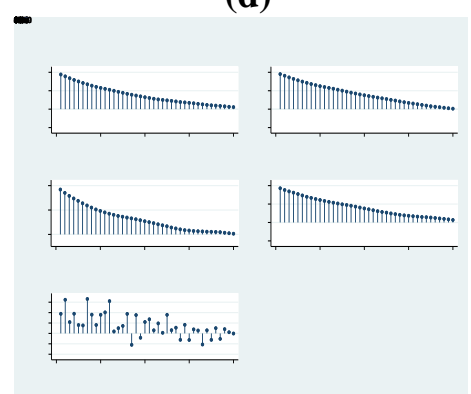

others, the reasons of the status quo lie in a low technological level, slow technical changes, weak spillover effects, and few high-tech enterprises. As claimed by Pereira (2003), Karagiannis et al. (2004), and Palivos and Karagiannis (2014), and many others, the ES lower than one points at the domination of diminishing marginal productivities in the economy and hence it are not capable of generating the unbounded endogenous growth. From these discussions, to encourage investments in physical and human capital as well as $R \& D$ activities in enterprises in a high-quality institutional environment is extremely important in emerging economies.

(ii) Since $g_{l}<g_{K}$ and $\frac{K}{L}>1$, the higher rate of economic growth is correlated to a greater ES, i.e., $\frac{\delta g_{y}}{\delta \sigma}>0$. With an ES lower than one according to our results, capital as a relatively scarce factor more strongly impacts on the aggregate product for its elasticity of production is large $(\approx 0.7)$. With the rising ES, the elasticity of production will be decreasing for capital, but it will grow for labor. Capital is scarce in such emerging economies as Vietnam, thus to significantly raise private investments must be one of effective growth policies. In particular, Vietnam needs to attract more foreign direct investment, specifically in hightechnology industries and increase positive spillover effects from foreign firms to national ones. Along 
with the above mentioned policies, an indispensable measure is to increase the efficiency of public investment.

\section{Conclusion}

With the purpose to test the possibility of endogenous growth for the Vietnamese economy, the present study applies the Bayesian non-linear regression via the Random-walk MH algorithm and Gibbs sampling to estimate the ES of the aggregate CES production function for Vietnam's economy. The Bayesian approach employed in this work has some advantages over most past studies applying the standard frequentist methods. The former provides more robust estimation than the latter due to combining prior information with observed data in a posterior model. More importantly, Bayesian inference gives the intuitive probability interpretation of estimation results, which a frequentist framework cannot do. That is a full posterior distribution of parameter estimates. The CES was selected over the Cobb-Douglas for its presumptions are more flexible, and specifically, its ES can provide useful implications for economic growth. Moreover, the CES is adaptable to a sample period in empirical analysis. Macro data on real GDP, real capital stock, and labor input covered the 2000-2016 period. The results of robustness checks indicate that the MCMC chains have converged to the target distribution and so the Bayesian inference is valid. According to the empirical results, the CES function specified is a neoclassical one, where a constant ES is lower than one, or in other words, capital and labor are complementary. The explanations for the empirical findings were provided based on the modern growth theories. In the end, the author went to an insightful conclusion that in the long-term, the Vietnamese economy can be slowing down with respect to the rate of economic growth in the presence of the law of positive and diminishing productivities. To counteract this tendency, Vietnam needs to concurrently substantially increase investments, including foreign, and to enhance the accumulation of human capital, and strongly intensify R\&D activities and technology transfers in order to raise the level of mechanization as well as the effects of technical progress on production. Last but not least, to improve institution quality to accelerate knowledge spillover effects across the corporate sector must be a great need in developing and emerging countries.

The main limitation of the research is that our model did not include human capital. We suggest incorporating this factor as either disembodied or embodied technical change in future models.

Funding: This research is supported by the Banking University HCMC, Vietnam.

Acknowledgments: The author is thankful to the anonymous referees for very useful comments.

Conflicts of Interest: The author declares no conflict of interest.

\section{References}

[1] Anh L.H., Kreinovich V., and Thach N.N., eds., Econometrics for Financial Applications. Cham: Springer, 2018.

[2] Antras, Pol., Is the U.S. Aggregate Production Function Cobb-Douglas? New Estimates of the Elasticity of Substitution, Contributions to Macroeconomics, 4(1), 2004, pp.1-34.

[3] Arrow, Kenneth J., Hollis B. Chenery, Bagicha Singh Minhas, and Robert M. Solow, Capital Labour Substitution and Economic Efficiency, Review of Econ. and Statistics, 63,1961, pp. 225-50.

[14] Arrow, Kenneth J., The Economic Implications of Learning by Doing, Review of Economic Studies, 29 (June), 1962, pp.155-173.

[15] Azariadis, Costas, Intertemporal Macroeconomics, Hoboken: Blackwell Publishers, 1993.

[16] Barkai, Haim, Ricardo on Factor Prices and Income Distribution in a Growing Economy, Economica, 26, 1959, pp. 240-50.

[17] Barro, Robert J., and Xavier Sala-i-Martin, Economic Growth. New York: McGraw-Hill, 1995.

[18] Berndt, Ernst, Reconciling Alternative Estimates of the Elasticity of Substitution, Review of Economics and Statistics, 58, 1976, pp. 59-68.

[19] Bodkin, Ronald G., and Laurence R. Klein, Nonlinear Estimation of Aggregate Production Functions, Review of Economics and Statistics, 49(1), 1967, pp. 28-44.

[20] Briggs, William and Hung T. Nguyen, Clarifying ASA's View on P-Values in Hypothesis Testing, Asian Journal of Economics and Banking, 3(2), 2019, pp. 1-16.

[21] Cobb, Charles W., and Paul H Douglas, A Theory of Production, American Economic Review 18, 1928, pp.139-65.

[22] Cronin, Francis J., Elisabeth Colleran, and Mark Gold, Telecommunications, factor substitution and economic growth, 
Contemporary Economic Policy, 15, 1997, pp. 21-31.

[23] Federal Reserve Bank of St. Louis, Penn World Table, 2019. Available online: https://fred.stlouisfed.org.

[24] Ferguson, C., The elasticity of substitution and the savings ratio in the neoclassical theory of growth, Quarterly Journal of Economics, 79(3), 1965), pp. 465-71.

[25] Galor, Oded, Convergence? Inference from theoretical models, Economic Journal, 106, 1995, pp. 1056-69.

[26] Hamermesh, Daniel, Labor Demand. Princeton: Princeton University Press, 1993.

[27] Heubes, Jurgen, Elasticity of substitution and growth rate of output, The German Economic Review, 10, 1972, pp. 170-75.

[28] Humphrey, Thomas M., Algebraic Production Functions and their Uses before CobbDouglas. Federal Reserve Bank of Richmond, Economic Quarterly, 83, 1997, pp. 51-83.

[29] Hung T. Nguyen, Nguyen Duc Trung, and Nguyen Ngoc Thach, Beyond Traditional Probabilistic Methods in Econometrics, In Beyond Traditional Probabilistic Methods in Economics, ECONVN 2019, Studies in Computational Intelligence, vol 809, Springer, Cham. https://doi.org/10.1007/978-3-03004200-4_1

[30] Huynh, The Nguyen, Factors affecting technical efficiency in Vietnamese small and medium enterprises, Journal of Asian Business and Economics Studies, 2019. Available online: http://jabes.ueh.edu.vn/Home/SearchArticle?arti cle $I d=8$ fbfecc6-ffc8-4ab8-84b7-5ca9b1ab8c50 (accessed on 11 January 2020).

[31] Kamien, Morton I., and Nancy L. Schwartz, Optimal "induced" technical change, Econometrica, 36, 1968, pp. 1-17.

[32] Karagiannis Giannis, Palivos Theodore, and Papageorgiou Chris, Variable Elasticity of Substitution and E conomic Growth: Theory and Evidence, New Trends in Macroeconomics, 2004. DOI: 10.1007/3-54028556-3 2

[33] Khuc, Van Quy, and Tran Quang Bao, Identifying the determinants of forestry growth during the 2001-2014 period, Journal of Agriculture and Rural Development, 12, 2016, pp. 2-9

[34] Klump, R., de La Grandville, O., Economic growth and the elasticity of substitution: Two theorems and some suggestions, American Economic Review, 90, 2000, pp. 282-291
[35] Klump, R., Preissler, H., CES production functions and economic growth, Scandinavian Journal of Economics, 102, 2000, pp. 41-56

[36] Kreinovich, V., Thach, N.N., Trung, N.D., and Thanh, D. Van, eds. Beyond Traditional Probabilistic Methods in Economics, Cham: Springer, 2019.

[37] Lagomarsino, Elena, A Study of the Approximation and E stimation of CES Production Functions. Ph.D. thesis, HeriotWatt University, Edinburgh, Scotland, 2017.

[38] La Grandville, O., In quest of the Slutsky Diamond, American Economic Review, 79, 1989, pp. 468-481

[39] Lambert, Paul C., Sutton, Alex J., Burton, Paul R., Abrams, Keith R., and David, R. Jones, How vague is vague? A simulation study of the impact of the use of vague prior distributions in MCMC using WinBUGS. Statist. Med., 24, 2005, pp. 2401-2428.

[40] Lloyd, Peter J., Elementary Geometric/Arithmetic Series and Early Production Theory, Journal of Political Economy, 77, 1969, pp. 21-34.

[41] McFadden, Daniel, Estimation Techniques for the Elasticity of Substitution and Other Production Parameters. North Holland, Contributions to economic analysis, 2, 1978, pp. 73-123.

[42] Mizon, Grayham E., Inferential procedures in nonlinear models: An application in a UK industrial cross section study of factor substitution and returns to scale, Econometrica, 45, 1977, pp. 1221-42.

[43] Nerlove, Marc, Recent Empirical Studies of the CES and Related Production Functions, The Theory and Empirical Analysis of Production, 31, 1967, pp. 55-136.

[44] Nguyen, Quang Hiep, Sources of province Hung Yen's economic growth, Journal of Economic Development, 275, 2013, pp. 28-39.

[45] Palivos Theodore and Karagiannis Giannis, The Elasticity of Substitution in Convex Models of Endogenous Growth. Political Economy Perspectives on the Greek Crisis-Debt, Austerity and Unempoyment View Project, 2004.

https://www.researchgate.net/profile/Theodore _Palivos/publication/27382259_The_Elasticity _of_Substitution_in_Convex_Models_of_Endo genous_Growth/links/0912f5093e536e81f7000 000/The-Elasticity-of-Substitution-in-ConvexModels-of-Endogenous-Growth.pdf

[46] Pereira, Claudiney M., Empirical Essays on the Elasticity of Substitution, Technical Change, 
and Economic Growth, Ph.D. dissertation, North Carolina State University, Raleigh, NC, USA, 2003.

[47] Pitchford, John D., Growth and the elasticity of substitution, Economic Record, 36, 1960, pp. 491-503.

[48] Pham, Le Thong, and Phuong Thuy Ly, Technical efficiency of Vietnamese manufacturing enterprises, Journal of Economics and Development, 229, 2016, pp. 43-51.

[49] Roberts, Gareth O., and Jeffery S. Rosenthal, Optimal scaling for various MetropolisHastings algorithms, Statistical Science, 16, 2001, pp. 351-67.

[50] Romer, Paul M., Increasing Returns and LongRun Growth, Journal of Political Economy, 94, 5(October), 1986, pp. 1002-1037.

[51] Romer, Paul M., Crazy Explanations for the Productivity Slowdown, NBER Macroeconomics Annual, Cambridge: MIT Press, 1987.

[52] Samuelson, Paul A., Paul Douglas's Measurement of Production Functions and Marginal Productivities, Journal of Political Economy, 87, 1979, pp. 923-39.

[53] Sato, K., Growth and the elasticity of factor substitution: A comment - how plausible is imbalanced growth, Economic Record, 39, 1963, pp. 355-61.

[54] Schumpeter, Joseph A., History of Economic Analysis, London: Allen \& Unwin, 1954.

[55] Solow, Robert M., A Contribution to the Theory of Economic Growth, Quarterly Journal of Economics, 70, 1(February), 1956, pp. 65-94.

[56] Solow, Robert M., Technical Change and the Aggregate Production Function, The Review of Economics and Statistics, 39, 1957, pp. 31220.

[57] Solow, Robert M., Learning from "learning by doing", Lessons for Economic Growth, Stanford, CA: Stanford University Press, 1997.

[58] Stigler, George J., The Ricardian Theory of Value and Distribution, Journal of Political Economy, 60, 1952, pp. 187.

[59] Swan, Trevor W., Economic Growth and Capital Accumulation, The Economic Record 32 (November), 1956, pp. 334-361.

[60] Thach, N.N., Recovering from the Recession: A Bayesian Change-Point Analysis. In: Thach N.N, Kreinovich V, Trung N.D. (eds), Data Science for Financial Econometrics, ECONVN2020, Studies in Computational
Intelligence, vol. 898, Springer, Cham, 2020a. to appear.

[61] Thach, N.N., The Variable Elasticity of Substitution Function and Endogenous Growth: An Empirical Evidence from Vietnam, International Journal of Economics and Business Administration, VIII(1), 2020b; pp. 263-277.

[62] Thach, N.N., How to Explain when the ES is Lower than One? A Bayesian Nonlinear MixedEffects Approach, J. Risk Financial Manag, 13(2), (2020c), 21. https://doi.org/10.3390/jrfm13020021

[63] Tu, Thai Giang, and Phuc Tho Nguyen, Using the Cobb-Douglas to analyze the impact of inputs on coffee productivity in province DakLak, Journal of Economics and Development, 8, 2012, pp. 90-93.

[64] Velupillai, Kumaraswamy, The Cobb-Douglas or the Wicksell Function?-A Comment, Economy and History, 16, 1973, pp. 111-13.

[65] Vietnamese General Statistics Office, Dan so va lao dong, 2019. Available online: https://gso.gov.vn/default.aspx?tabid=714.

[66] Yang Ruoyong and Berger Jam es O., A Catalog of Noninformative Priors, 1998. https://www.semanticscholar.org/paper/ACatalog-of-Noninformative-Priors-YangBerger/f75f2549f7a273432cbe365e94d26a4b0e 494281

[67] Yuhn, Ky-hyang, Economic growth, technical change biases, and the elasticity of substitution: A test of the la grandville hypothesis, The Review of Economics and Statistics, 73, 1991, pp. 340-46. 